\title{
Evaluation of local aggressive lung therapy versus systemic therapy in oligometastatic non-small cell lung cancer: a systematic review and meta-analysis
}

\author{
Chenxi Zhang ${ }^{1 \#}$, Nan Ma ${ }^{2 \#}$, Qitong Zhang ${ }^{3 \#}$, Kaifu Zheng ${ }^{1}$, Chuang Sun ${ }^{4}$, Xiyang Tang ${ }^{1}$, Xiaofei $\mathrm{Li}^{1}$, \\ Jinbo $\mathrm{Zhao}^{1 \wedge}$
}

${ }^{1}$ Department of Thoracic Surgery, Tangdu Hospital, Air Force Medical University, Xi'an, China; ${ }^{2}$ Department of Ophthalmology, Tangdu Hospital, Air Force Medical University, Xi'an, China; ${ }^{3}$ School of Stomatology, Xi'an Medical University, Xi'an, China; ${ }^{4}$ Department of Cardiology, Xi'an International Medical Center Hospital, Xi'an, China

Contributions: (I) Conception and design: C Zhang, N Ma, Q Zhang, X Li, J Zhao; (II) Administrative support: X Li, J Zhao; (III) Provision of study materials or patients: X Li, J Zhao; (IV) Collection and assembly of data: C Zhang, N Ma, Q Zhang, K Zheng, C Sun, X Tang; (V) Data analysis and interpretation: All authors; (VI) Manuscript writing: All authors; (VII) Final approval of manuscript: All authors.

\#These authors contributed equally to this work.

Correspondence to: Jinbo Zhao; Xiaofei Li. Department of Thoracic Surgery, Tangdu Hospital, Air Force Medical University, No. 569, Xinsi Road, Xi'an 710038, China. Email: zhaojinbo@aliyun.com; lxfchest@fmmu.edu.cn.

Background: Previous studies have shown the feasibility and effectiveness of local aggressive thoracic therapy (surgery and radiotherapy) for oligometastatic non-small cell lung cancer compared with systemic therapy, but with small sample. This study aims to perform a pooled analysis to explore whether LT could improve outcomes of oligometastatic patients with non-small cell lung cancer.

Methods: Protocol of present study was registered on PROSPERO as number: CRD42021233095. PubMed, Embase and Web of knowledge were searched, and eligible studies investigating local therapy for non-small cell lung cancer with 1-5 metastases regardless of organs were included. Linear regression between survival and clinical characteristics were conducted. Hazard ratios of survival and adverse effects were merged. Pooled survival curves were carried out.

Results: Three randomized controlled trials and 5 cohort studies enrolling 499 patients were included. There was a trend that median overall survival declined with the increasing proportion of N2-3 positive patients in local therapy group, but with no statistical difference $\left(\mathrm{P}=0.09, \mathrm{R}^{2}=0.98\right)$. Undergoing local therapy for oligometastatic non-small cell lung cancer achieved reduction of $47 \%$ and $60 \%$ in the risk of death and cancer progression $(\mathrm{P}<0.001)$, respectively. In subgroup analysis, patients receiving local therapy including surgery showed hazard ratio of 0.33 on progression-free survival and 0.55 of these excluding surgery. Patients receiving consolidative local therapy (local therapy after systemic therapy) obtained hazard ratios 0.33 and 0.45 on progression-free and overall survival $v$ s. systemic therapy, respectively. Hazard ratios of those receiving upfront local therapy (local therapy first) were 0.62 and 0.68 on progression-free and overall survival $v s$ systemic therapy. Pooled survival analysis showed median overall and progression-free survival of local therapy (21.6 and 14 months) group were both longer than systemic one (14.3 and 6.5 months). Odds ratio of adverse effects were no difference between 2 groups $(\mathrm{P}=0.16)$.

Conclusions: Local aggressive thoracic therapy could prolong 7 months overall and progressionfree survival compared with systemic therapy in patients with oligometastatic non-small cell lung cancer. Consolidative local therapy might be a more favorable choice of local therapy. Benefits of local therapy for $\mathrm{N} 2-3$ positive patients should explored further.

Keywords: Non-small cell lung cancer (NSCLC); oligometastasis; surgery; radiotherapy; meta-analysis

\footnotetext{
^ ORCID: Chenxi Zhang, 0000-0001-8785-708X; Jinbo Zhao, 0000-0002-7806-6072.
} 
Submitted Jun 09, 2021. Accepted for publication Aug 13, 2021.

doi: $10.21037 /$ jtd-21-957

View this article at: https://dx.doi.org/10.21037/jtd-21-957

\section{Introduction}

Non-small cell lung cancer (NSCLC) is the leading cause of cancer-related deaths around world, about $40 \%$ of them are stage IV at diagnosis (1). Systemic therapies (ST) are recommended for these patients (2). However, few patients survived more than 5 years though with the remarkable development of targeted therapy and immunotherapy (3).

Oligometastases is an intermediate state between localized and disseminated cancer proposed by Hellman and Weichselbaum (4). Approximately $25 \%$ of stage IV NSCLC patients present with oligometastases (5). A series of cohort studies (6-8) and several randomized controlled trials (RCT) (9-11) showed the effectiveness of local aggressive thoracic therapy (LT) including radiotherapy (RT) and surgery on prolonging survival compared with systemic therapy for oligometastatic NSCLC patients. Nonetheless, due to the restrict recruitment and heterogeneity of stage IV disease, these studies were with small sample size and not long enough follow-up time.

To further explore the current situation and effectiveness of local aggressive thoracic therapy for oligometastatic NSCLC, it is important to make a pooled analysis and provide more information for future design.

We present the following article in accordance with the PRISMA reporting checklist (available at https://dx.doi. org/10.21037/jtd-21-957).

\section{Methods}

Protocol of present study was registered on PROSPERO as number: CRD42021233095.

\section{Searching strategy}

PubMed, Embase and Web of knowledge were searched from January 2001 to December 2020 by two reviewers (Chenxi Zhang and Nan Ma). Searching strategy was displayed as Table S1.

\section{Study selection}

Two reviewers screened studies according to pre-specified criteria independently. Consensus was discussed by two reviewers and another researcher (Qitong Zhang).

Present study was designed to enroll oligometastatic NSCLC as 1-5 metastatic lesions regardless of organs $(9,10,12)$. LT was defined as surgery, stereotactic body radiotherapy with $>20 \mathrm{~Gy}$, beam radiotherapy with dose $>45$ Gy combined with or without ST. ST included chemotherapy, targeted therapy and immunotherapy. Palliative radiotherapy was permitted in systemic cohort with intent to relief symptoms and dose lower than local therapy cohort.

Studies meet the following criteria were included: (I) RCT or cohort studies comparing the effectiveness of local aggressive thoracic therapy and systemic therapy for oligometastatic NSCLC patients; (II) Hazard ratio of death or disease-progression could be retrieved; (III) KaplanMeier curve of overall or progression-free survival was reported. The exclusion criteria were as follow: (I) small cell lung cancer; (II) study with less than 10 cases; (III) palliative RT in systemic group with no clear statement of dose and intent; (IV) unbalanced local treatment for metastases, such as a cohort of lung LT treated patients compared with a cohort of lung ST but metastases LT treated patients.

\section{Data extraction and risk of bias}

All data were extracted by two independent reviewers. First author, year of publication, study type, sample size, eligible criteria, clinical characteristics of patients, treatment strategy, median overall survival time (OS), median progression-free survival time (PFS), hazard ratios (HR) and number of adverse events were retrieved from original studies as reported. HR could be estimated by data extraction of Kaplan-Meier curve (13), if not mentioned. Pooled survival time and survival curve were generated by methods reported (14).

Cochrane risk table was used to evaluate the bias of RCT. Newcastle-Ottawa scale was used for assessing cohort studies, and 6 or more points were considered as high quality.

\section{Statistical analysis}

The primary endpoint was OS, second endpoints were 


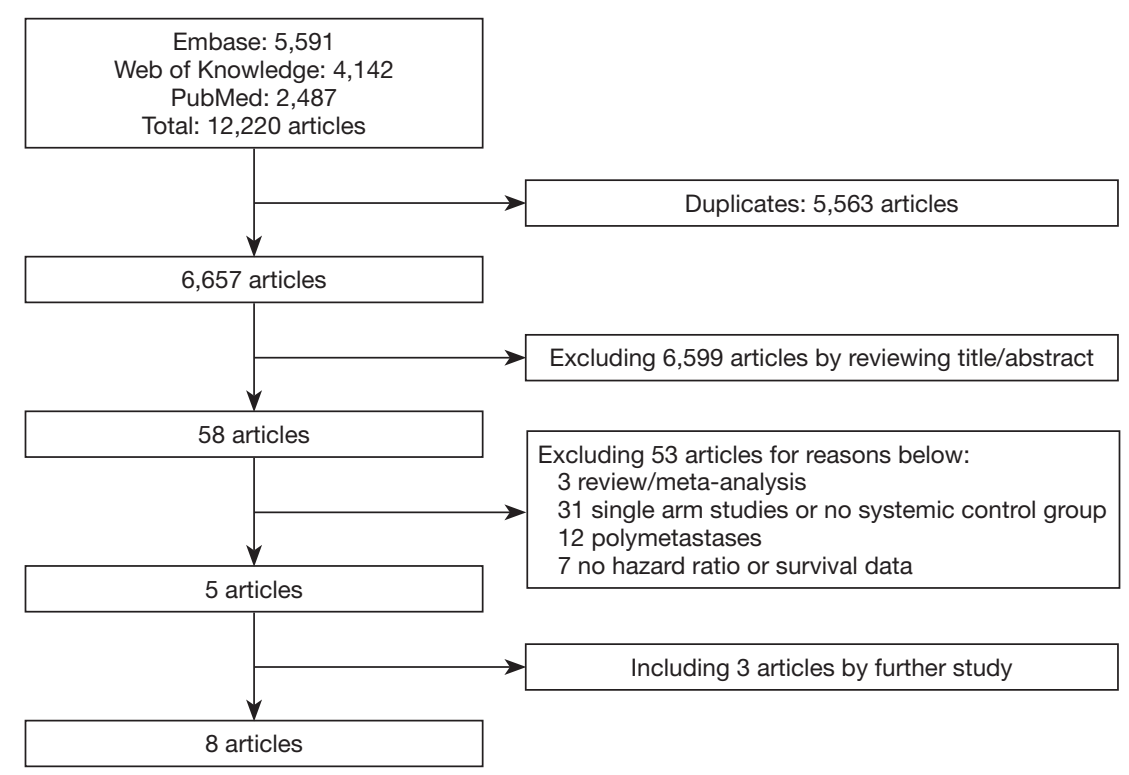

Figure 1 Flowchart of study selection.

PFS and adverse effects. The calculation of HR was performed by Revman (Version 5.4, The Cochrane Collaboration, http://ims.cochrane.org/revman). Statistical analysis was made under fixed effect model, other than random effect model with considerable heterogeneity. $\mathrm{I}^{2}>25 \%$ was regarded as mediate heterogeneity, and $>50 \%$ as considerable heterogeneity. Sensitivity analysis was performed by enrolling RCT and high quality cohort studies. A P value below 0.05 was considered as statistical difference.

Data extraction of Kaplan-Meier survival curve was performed by "Engauge Digitizer" (Version 12.1, http://digitizer.sourceforge.net). Linear regression and pooled survival was performed by $\mathrm{R}$ software (Version 4.0.3, r-project, http://www.r-project.org). R package "MetaSurvival" (Version 0.1.0, http://github.com/ shubhrampandey/metaSurvival) was used to calculated cumulative survival rate and package "ggplot2" (Version 3.3.3, http://ggplot2.tidyverse.org) was used to generate regression and survival curve.

\section{Results}

\section{Searching results}

Totally 12,220 articles were screened based on searching strategy, and 5,563 duplicates were excluded and 6,599 were exclude after reviewing title and abstract. By assessing full- text and further study, 8 articles were retrieved for final analysis. The selection procedure was displayed as Figure 1.

\section{Baseline characteristics and risk assessment}

Totally 3 RCT $(9,10,12)$ (2 published studies and 1 conference abstract) and 5 retrospective cohort studies (RCS) (15-19) (all published) were included. For study type, 6 studies were single center analysis and 2 were multicenter. All patients were selected based on histologically proven NSCLC. Performance score (KPS $\geq 70$ or ECOG $\leq 2$ ) were the most common criteria for recruitment of patients (in 6 studies). With regard to definition of oligometastases, 1 study proposed that 1 lesion in 1 organ, 1 study proposed 1-4 lesions in 1 organ, 1 study suggested 1-5 lesions in 1 organ and 1 suggested $1-3$ lesions (counting positive lymph nodes) regardless of organ. These 4 studies all implemented surgery as component of treatment strategy. The remaining 4 studies using RT as the only way of LT, defined oligometastases as 1-5 lesions ignoring number of organs involved. For systemic therapy, 5 studies were based on chemotherapy only, 1study contained both chemotherapy and targeted therapy and 2 studies used targeted therapy alone. Three studies reported LT for lung only, and 5 studies applied LT for both lung and metastases (Table 1).

Totally 499 patients were included in this analysis, 253 (50.7\%) were in LT group and 246 (49.3\%) were in ST 
Table 1 Baseline characteristics of included studies

\begin{tabular}{|c|c|c|c|c|c|c|}
\hline Study & Period & Type of study & Eligibility & Intervention & LT sites & Outcomes \\
\hline $\begin{array}{l}\text { Xanthopoulos } \\
2015\end{array}$ & 2004-2010 & RCS/Single & $\begin{array}{l}\text { pNSCLC, } 1-4 \text { lesions regardless of organ, } \\
E C O G \leq 2\end{array}$ & $\begin{array}{l}\mathrm{CH}+\mathrm{RT}: 25 \\
\mathrm{CH}: 50\end{array}$ & Lung & OS, AE \\
\hline Huang 2017 & 2001-2015 & RCS/Single & $\begin{array}{l}\text { pNSCLC, single lesion, adrenal } \\
\text { metastases }\end{array}$ & $\begin{array}{l}\text { Surgery: } 10 \\
\mathrm{CH}: 12\end{array}$ & $\begin{array}{l}\text { Lung + } \\
\text { metastases }\end{array}$ & os \\
\hline lyengar 2018 & 2014-2016 & $\begin{array}{l}\text { RCT/Single/ } \\
\text { Phase II }\end{array}$ & $\begin{array}{l}\text { pNSCLC, stable disease after first-line } \\
\mathrm{CH}, \leq 5 \text { extra-brain distant metastases } \\
\text { regardless of organs involved, KPS } \geq 70 \text {, } \\
\text { TKI naïve, no untreated brain lesion or } \\
\text { involving gastrointestinal/skin metastases }\end{array}$ & $\begin{array}{l}\mathrm{CH}+\mathrm{SBRT}+\mathrm{MCT}: \\
14 \\
\mathrm{CH}+\mathrm{MCT}: 15\end{array}$ & $\begin{array}{l}\text { Lung + } \\
\text { metastases }\end{array}$ & $\begin{array}{l}\text { PFS, OS, AE, } \\
\text { recurrence, } \\
\text { metastases }\end{array}$ \\
\hline Xu 2018 & 2010-2016 & RCS/Single & $\begin{array}{l}\text { pNSCLC, EGFR+, } \leq 5 \text { metastases } \\
\text { regardless of organs, ECOG } \leq 2 \text {, stable } \\
\text { after first-line EGFR TKI }\end{array}$ & $\begin{array}{l}\text { TKI + Surgery/RT: } 51 \\
\text { TKI: } 39\end{array}$ & $\begin{array}{l}\text { Lung }+ \\
\text { metastases }\end{array}$ & PFS, OS, AE \\
\hline Gomez 2019 & 2012-2016 & $\begin{array}{l}\text { RCT/Multi/ } \\
\text { Phase II }\end{array}$ & $\begin{array}{l}\text { pNSCLC, age } \geq 18, \leq 3 \text { lesions regardless } \\
\text { of organs, positive } L N \text { counted as } \\
\text { metastasis, ECOG } \leq 2 \text {, after standard first- } \\
\text { line ST, no bevacizumab in } 2 \text { weeks }\end{array}$ & $\begin{array}{l}\mathrm{CH} / \mathrm{TKI}+\text { Surgery/RT } \\
+\mathrm{MT}: 25 \\
\mathrm{CH} / \mathrm{TKI}+\mathrm{MT}: 24\end{array}$ & $\begin{array}{l}\text { Lung + } \\
\text { metastases }\end{array}$ & PFS, OS, AE \\
\hline Wang 2020 & 2016-2019 & $\begin{array}{l}\text { RCT/Multi/ } \\
\text { Phase III }\end{array}$ & $\begin{array}{l}\text { pNSCLC, EGFR+, } \leq 5 \text { metastases, ECOG } \\
\leq 2 \text {, systematic therapy naïve, no brain } \\
\text { lesion at randomization }\end{array}$ & $\begin{array}{l}\text { Upfront SRS + TKI: } \\
68 \\
\text { TKI: } 65\end{array}$ & $\begin{array}{l}\text { Lung + } \\
\text { metastases }\end{array}$ & PFS, OS, AE \\
\hline
\end{tabular}

RCT, random controlled trials; RCS, retrospective cohort studies; Single, single-center study; Multi, multi-center study; NSCLC, nonsmall cell lung cancer; ECOG, eastern cooperative oncology group; EGFR, epidermal growth factor receptor; TKI, tyrosine kinase inhibitor; KPS, Karnofsky performance score; CH, chemotherapy; SBRT, stereotactic body radiotherapy; SRS, stereotactic radio-surgery; $\mathrm{RT}$, radiotherapy; MT, maintenance therapy; $\mathrm{MCT}$, maintenance chemotherapy; PFS, progression-free survival; OS, overall survival; AE, adverse events.

group. The median age of LT patients ranged from 55 to 63 years, while 58 to 70 years of ST. Four studies enrolling 253 patients presented performance status. Of these patients, 90 (72.6\%) patients were with ECOG 0-1 point or KPS $\geq 80$ points in LT group, and corresponding number in ST group was $83(64.3 \%)(\mathrm{P}=0.159)$. There were 5 studies enrolling 225 patients reporting proportion of patients with $\mathrm{N} 2-3$ positive. Thirty-five $(28.7 \%)$ and 61 (59.2\%) patients were N2-3 positive in LT and ST group $(\mathrm{P}<0.001)$, respectively. Totally 6 studies containing 331 patients reported number of patients with single distant lesion. There were 88 (54.0\%) patients in LT group and 85 $(50.6 \%)$ patients in ST group with single distant metastasis $(\mathrm{P}=0.128)$. Only 4 studies presented median PFS, and 2 studies were lack of median OS in LT group due to not long enough follow-up time (Table 2, Table S2).

Among the 3 RCT, all studies were with high risk of binding procedure for the different implementation of LT and ST (Figure S1). For the 5 RCS, 1 study were considered as high quality with 6 points by Newcastle-Ottawa scale assessment (Table S3).

\section{Correlation between survival and clinical characteristics}

Linear regression showed that there was no correlation between proportion of patients with single metastatic lesion and survival, both in LT and ST groups (Figure S2). Same results were also presented between proportion of patients 


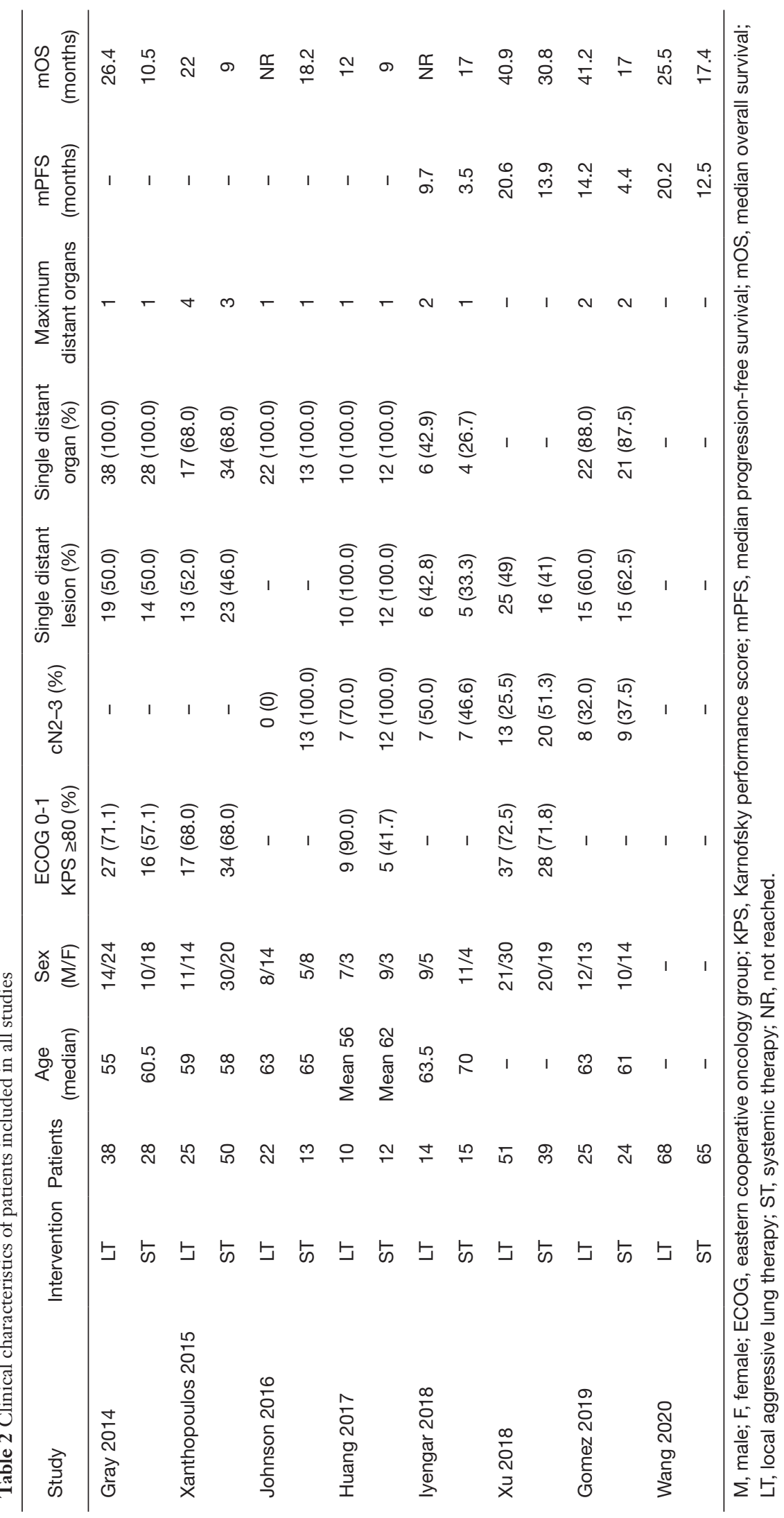



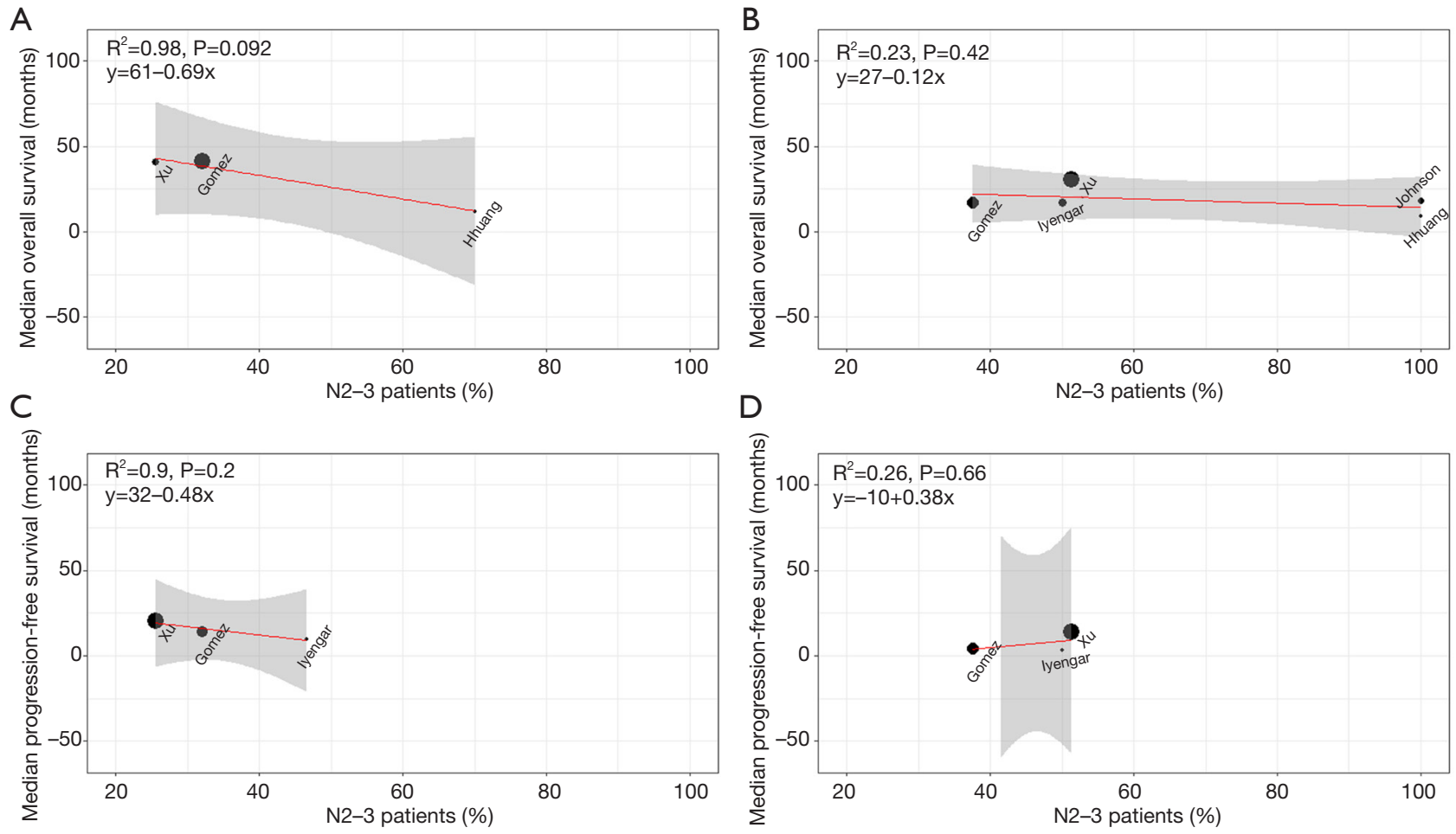

Figure 2 Correlationship between N2-3 status and median survival time by linear regression analysis. (A) N2-3 status and median OS in LT group; (B) N2-3 status and median OS in ST group; (C) N2-3 status and median PFS in LT group; (D) N2-3 status and median PFS in ST group. LT, local aggressive thoracic therapy; ST, systemic therapy; OS, overall survival; PFS, progression-free survival.

with N2-3 positive and corresponding survival in ST group. There was a trend that median OS declined with increasing proportion of $\mathrm{N} 2-3$ positive patients in LT group, but with no statistical difference $\left(\mathrm{P}=0.09, \mathrm{R}^{2}=0.98\right)$ (Figure 2).

\section{Cumulative survival and subgroup analysis}

LT for oligometastatic NSCLC patients achieved reduction of $47 \%$ (HR $=0.53,95 \% \mathrm{CI}: 0.43-0.65)$ and $59 \%$ (HR $=0.41,95 \%$ CI: $0.31-0.55)$ in the risk of death and cancer progression, respectively (Figure 3). No statistical difference was found of heterogeneity in both OS $\left(\mathrm{I}^{2}=11 \%, \mathrm{P}=0.35\right)$ and $\mathrm{PFS}\left(\mathrm{I}^{2}=36 \%, \mathrm{P}=0.19\right)$. All analysis was performed by fix effect model.

Six studies with applicable Kaplan-Meier curve of OS were enrolled for pooled analysis. The estimated pooled OS rate were $73.6 \%, 47.0 \%, 33.1 \%$ and $9.1 \%$ at the 1,2 , 3 and 5 -year in LT group. The corresponding OS rate in ST group were $53.5 \%, 25.2 \%, 9.8 \%$ and $0 \%$. Median OS of these 2 groups were 21.6 and 14.3 months, separately
(Figure 4A).

Three studies with available PFS curve were also pooled. The estimated pooled PFS rate were $56.3 \%, 18.2 \%$, $2.3 \%$ and $0.6 \%$ at the 1, 2, 3 and 4 -year in LT group. The corresponding PFS rate in ST group were $26.0 \%, 3.0 \%$, $0.7 \%$ and $0 \%$. Median PFS of these 2 groups were 14.0 and 6.5 months, respectively (Figure 4B).

In subgroup analysis, patients undergoing LT with or without surgery both showed benefits compared to those with ST on OS and PFS. Furthermore, patients receiving surgery as component of multi-modality therapy showed a lower HR of 0.33 (95\% CI: $0.22-0.48)$ on PFS compared to 0.55 (95\% CI: $0.36-0.83$ ) of these without surgery (Figure 5). For patients receiving consolidative LT (systemic therapy followed by local therapy), HRs were 0.33 (95\% CI: $0.23-0.47)$ and 0.45 (95\% CI: $0.34-0.60)$ on PFS and OS compared to ST ones. For patients receiving upfront LT (local therapy first), HRs were 0.62 (95\% CI: 0.39-0.99) and 0.68 (95\% CI: 0.47-1.00) compared to ST ones (Figure 6). Besides, studies were divided by 
A

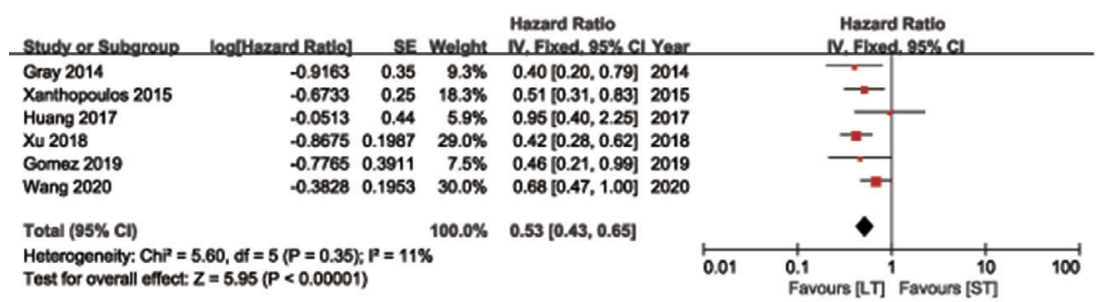

C

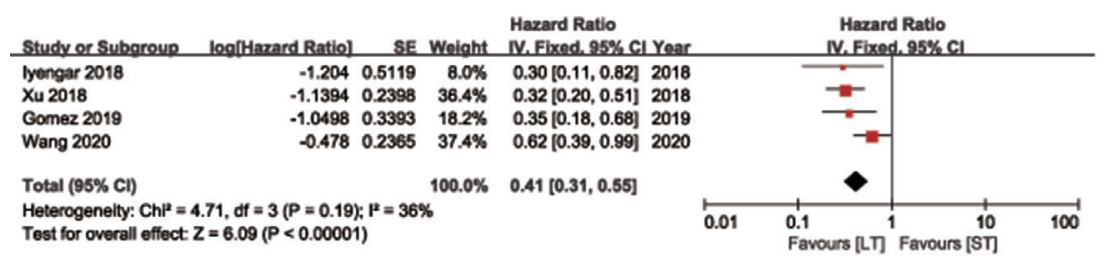

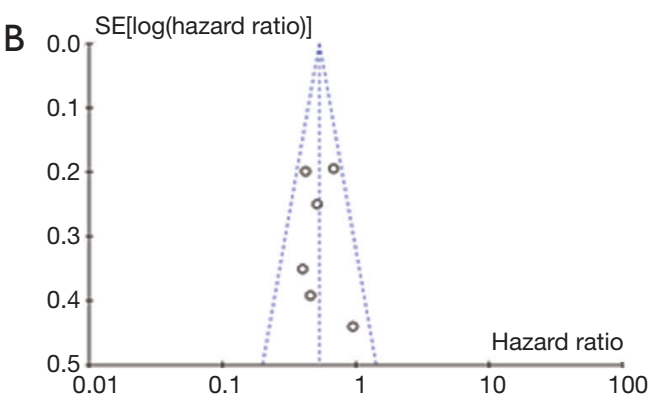

D SE[log(hazard ratio)]

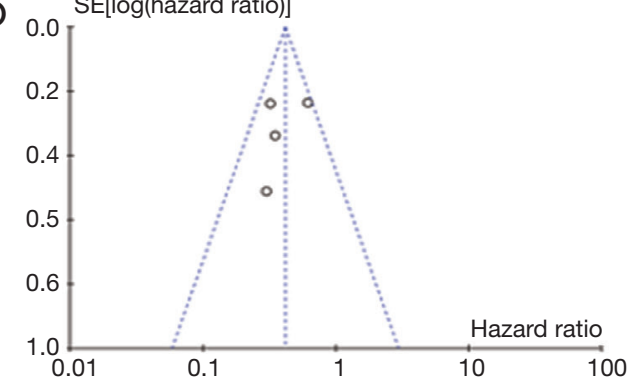

Figure 3 Forest plot of merged HR and funnel plot of studies included. (A) Forest plot of overall survival time; (B) Funnel plot of studies merged for overall survival; (C) Forest plot of progression-free survival time; (D) Funnel plot of studies merged for progression-free survival. HR, hazard ratio.

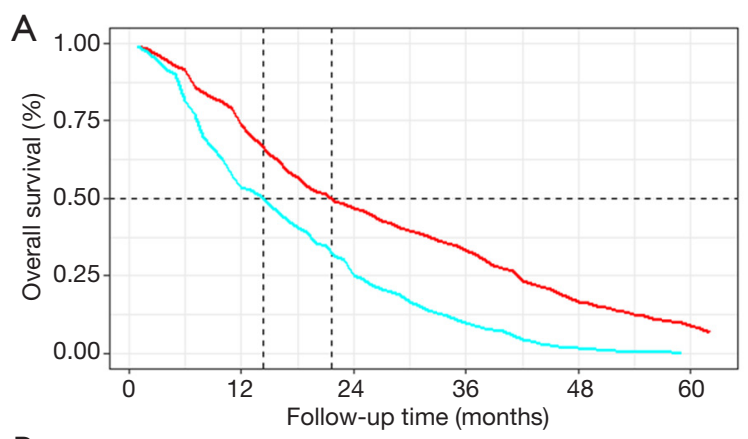

B

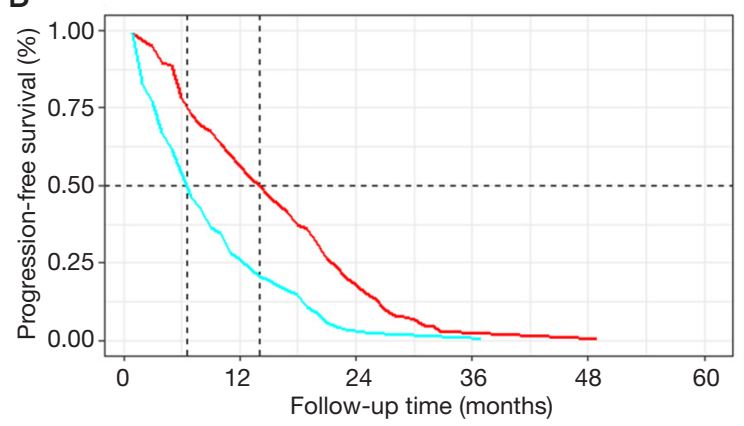

Figure 4 Pooled survival curve of local aggressive thoracic therapy and systemic therapy groups. (A) Pooled overall survival curve; (B) pooled progression-free survival curve. red line: local aggressive thoracic therapy group; blue line: systemic therapy group. study type (RCT and RCS), local treatment sites (LT for lung and LT for both lung and metastases) and systemic regimens (chemotherapy only or with targeted therapy). LT obtained more favorable survival in all subgroups (Figures S3-S5).

\section{Adverse effects}

There were 3 studies reported grade 3 or higher adverse effects of both LT and ST groups. The odds ratio of LT group was 1.84 (95\% CI: 0.79-4.29) compared with ST group, but with no statistical difference $(\mathrm{P}=0.16)$ (Figure $\mathrm{S} 6$, Table S4).

In addition, 2 studies reported toxicity induced by addition of LT. For about $8-17 \%$ of LT treated patients suffered grade 3 or higher pneumonitis and esophagitis (Table S5).

\section{Sensitivity analysis}

In sensitivity analysis, 3 RCT and 1 RCS were included. Pooled estimation confirmed the robust and stability of original conclusions (Figure S7). 
A

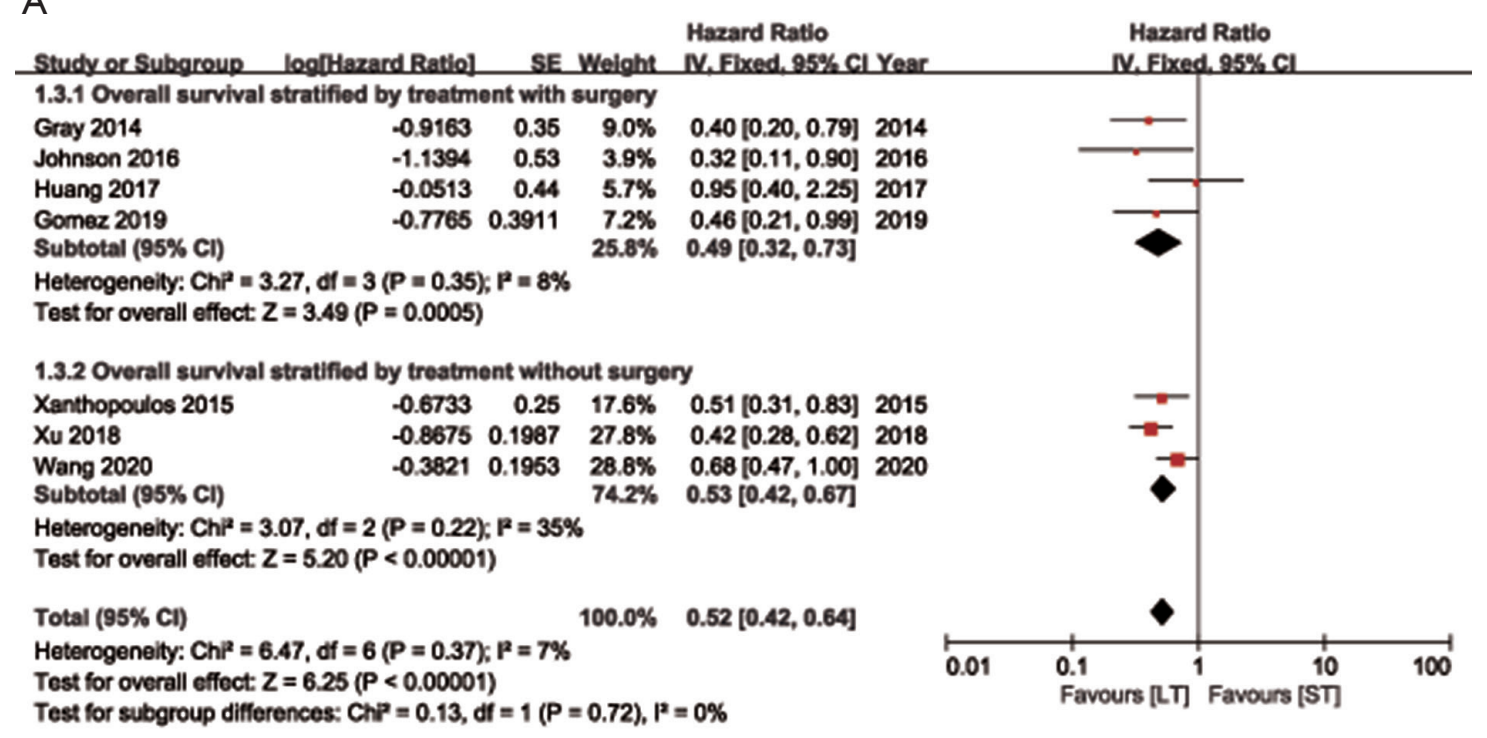

B

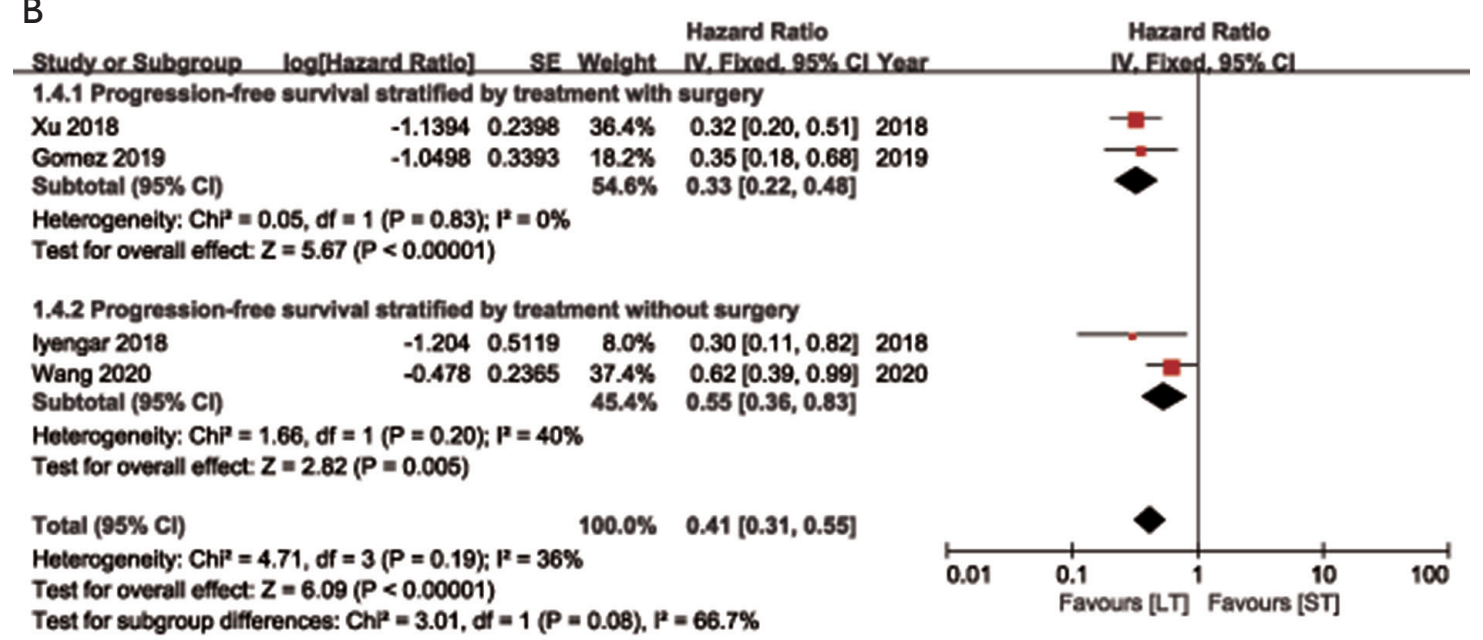

Figure 5 Subgroup analysis of included studies stratified by local aggressive thoracic therapy intervention type (with or without surgery). (A) Overall survival; (B) progression-free survival.

\section{Discussion}

To the best of our knowledge, this is the first meta-analysis enrolling RCT to compare local aggressive thoracic therapy and systemic therapy for patients with oligometastatic NSCLC. LT for oligometastatic NSCLC patients showed more benefits on reducing risk of death and cancer progression than ST. For primary endpoint, the OS was prolonged about 7 months in LT group. For secondary endpoint, LT favored PFS for about 7 months, and with acceptable adverse effects.
Up to now, the definition of oligometastases is still on debate (20). A systematic review analyzed the criteria of oligometastatic NSCLC in publications until now, and no formal definition was established in most of published studies. The upper number of lesion ranges from 1 to 8 with no limitation on organs involved (21). Present study was designed to enroll patients owing 1-5 metastases regardless of orangs which was consistent with majority of randomized controlled trials conducted in recent years $(9,10,12)$. The definition of oligometastases is decided by number of metastatic lesions and the number of metastatic organs. 
A

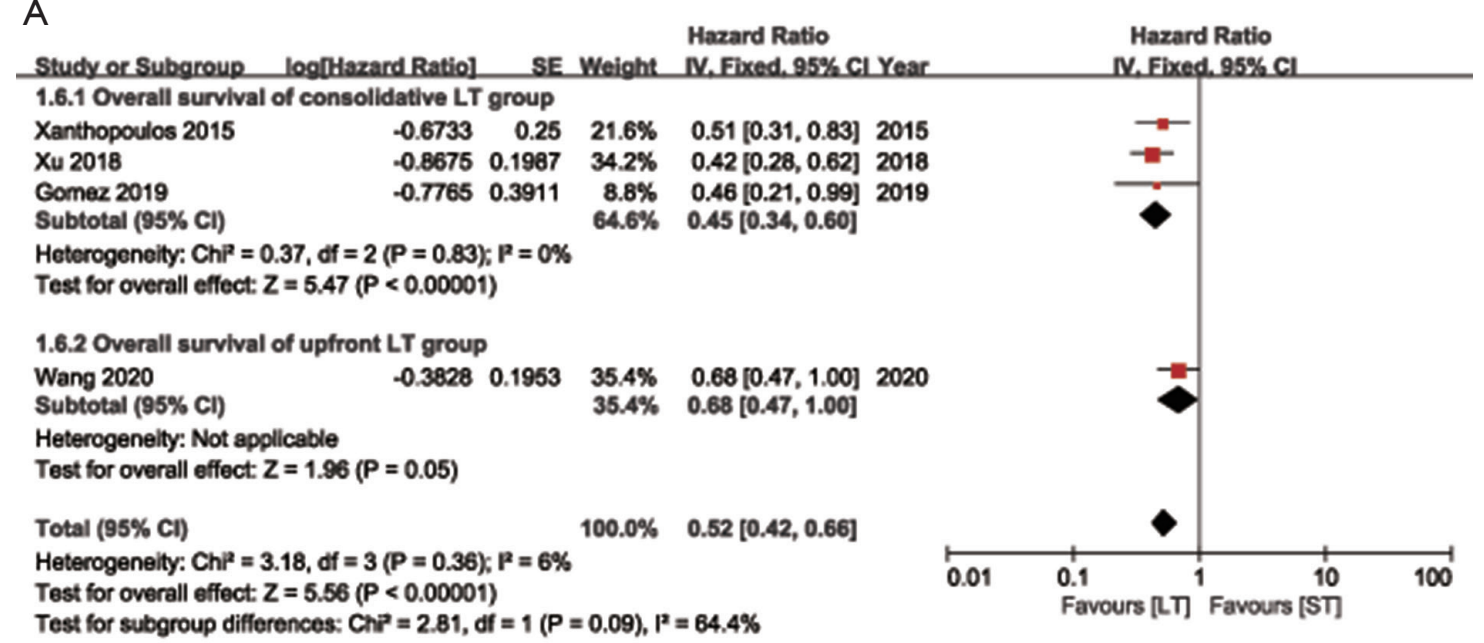

B

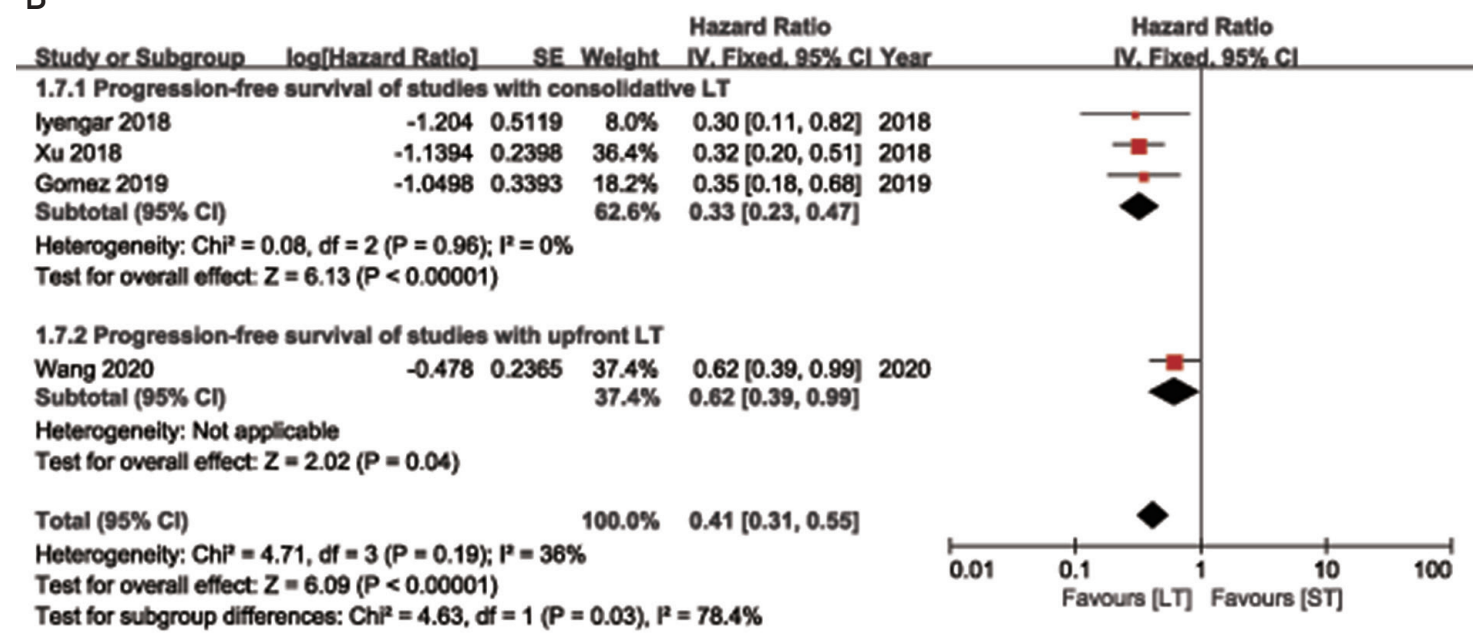

Figure 6 Subgroup analysis of included studies stratified by sequence of local aggressive thoracic therapy (consolidative local therapy or upfront local therapy). (A) Overall survival; (B) progression-free survival.

For metastatic lesions, more than $90 \%$ oligometastatic NSCLC patients were with 1 metastasis, and nearly $100 \%$ patients were with less than 5 metastases (21). In present meta-analysis, 6 studies enrolling 273 patients reported the number metastatic lesions, and approximately $70 \%$ were with single metastatic lesion. Single distant metastasis was categorized as M1b, which was considered to have more favorable survival than multiple metastases, in the 8th edition of TNM (tumor, node, and metastasis) classification (22). However, in the present study, proportion of single distant metastatic patient not impact the survival of studies included. Further subgroup analysis for patients with single metastasis between local therapy and systemic therapy could not be made for the lack of survival data in this subgroup. For metastatic organs, 5 studies enrolled in this study showed the maximum organs actually involved. Four of these five studies enrolled patients with no more than 2 organs involved. A more conservative definition of oligometastases (single organ) was used if surgery was taken as component of local therapy $(10,15,17,18)$. A panEuropean consensus reported a proposal of 1-5 metastatic lesions in no more than 3 organs may be an appropriate definition for oligometastases (23).

Positive mediastinal lymph node might be a contradictory for LT $(17,18)$. Several studies excluding N2 positive oligometastatic NSCLC patients from lung 
resection treatment due to possible detrimental survival $(17,24)$, Presence of mediastinal lymph nodes metastases indicated worse survival, and high proportion of $\mathrm{N} 2$ positive patients might result in a negative effect of lung resection on oligometastatic NSCLC patients $(18,25)$. However, same results were not reproduced when applying radiotherapy as non-invasive local treatment strategy $(9,16,26)$. Our linear regression analysis showed that OS of LT patients was decreased with the increasing proportion of N2-3 positive patients, though with no statistical difference. However, none of included studies compared survival between LT and ST patients in $\mathrm{N} 2-3$ positive subgroup. A consensus report proposed that mediastinal lymph nodes metastases was of importance in determining whether LT applied for oligometastatic NSCLC patients (23), and it should be further investigated in the future.

Good performance score is important for patient selection. Van den Begin and colleagues constructed a tool to select oligometastatic NSCLC patients for LT, and KPS performance score took the leading position to predict survival (27). In the present, 6 studies proposed ECOG $\leq 2$ or KPS $\geq 70$ as eligibility. Three RCT studies did not report the number of patients in each performance status point, but were designed with balanced recruitment of baseline characteristics. Four retrospective studies presented more than $70 \%$ of patients owing ECOG $0-1$ point or KPS $\geq 80$ points in LT group, but with no statistical difference compared with ST group $(\mathrm{P}=0.159)$. In addition, median ages of LT patients seemed slightly younger than ST ones (53-63 vs. 58-70). Younger patients may own better general condition to tolerate toxicity of LT, and it might be one of the reason that better survival was achieved in LT group.

Surgery and radiotherapy are both suitable choice for oligometastatic NSCLC patients. Previous study systematically reviewed LT for oligometastatic NSCLC regardless of surgery or radiotherapy, no significant difference of OS was found between these 2 approaches (21). In present study, both surgery and radiotherapy could obtain survival benefits compared with ST in subgroup analysis. However, a lower HR of 0.33 (95\% CI: $0.22-0.48$ ) on PFS was observed in studies including surgery as component of LT compared to 0.55 (95\% CI: 0.36-0.83) of those without surgery. Therefore, surgery still took an important role in LT application for oligometastatic NSCLC patients under suitable selection. It was worth noting that several studies enrolling $\mathrm{N} 3$ positive patients included surgery as local therapy, but presented scarce information of whether surgery was performed on these patients. For patients with
N3 positive status, radiotherapy for lung is recommended rather than surgery (2). Besides, clinical information and survival data of surgery and radiotherapy could not be retrieved from original study separately. A comparison between these two groups could not be achieved. Thus, the superiority comparison of surgery and radiotherapy for oligometastatic NSCLC should be explored by head-tohead study.

The sequence of LT and ST intervention is another key point for treatment strategy of oligometastatic NSCLC patients. Systemic therapy first could diminish tumor lesion to the maximum extent or screen out disease resistant to ST for recruiting suitable patients for further LT to avoid unnecessary injury or adverse events (7). However, delayed LT intervention might miss the opportunity of curative intent tumor elimination. On the contrary, removing tumor lesions directly could reduce tumor burden immediately to set the scene of following systemic therapy (26). Nevertheless, it may lead to unsuitable selection of patients with diffused cancer which are not detected yet. From this study, LT after first-line ST might be more beneficial for survival. There were three studies implement consolidative LT after first-line systemic therapy resulted an HR of 0.45 (95\% CI: 0.34-0.60) for OS compared with ST. It was also presented in the study conducted by Jones and colleagues that neo-adjuvant therapy resulting survival benefits for lung resected oligometastatic NSCLC patients (25). Only one study underwent LT before systemic therapy with an HR of 0.68, and the upper interval was 1.00 (95\% CI: 0.471.00). For its interim analysis nature, the survival advantage of upfront LT should be re-evaluated during the follow-up.

As to adverse effects, LT group showed a trend of more adverse events compared to ST group (HR $=1.84$, 95\% CI: 0.79-4.29), but with no statistical difference $(\mathrm{P}=0.16)$. Pneumonitis and esophagitis are most common adverse event of radiotherapy for about $8-17 \%$ patients $(16,19)$. Surgery related complications were reported as $9 \%$ in our center for stage IV NSCLC patients (28). This reminds us that candidates for LT should be with tolerance of toxicity after proper selection.

This study also has several limitations. Primarily, the study enrolled not only randomized controlled trials, but also retrospective cohort studies, for the scarcity of publications. Inherent biases existed in these retrospective studies, like unbalanced patients baseline characteristics between local therapy and systemic therapy groups. There were more $\mathrm{N} 2-3$ positive in systemic therapy cohort and more probable younger patients in local therapy cohort. 
More randomized controlled trials should be conducted and data of this meta-analysis should be updated in the future. Besides, due to the heterogeneity of stage IV NSCLC, such as patients with different metastatic sites, the results of pooled analysis should be interpreted cautiously. Furthermore, for the lack of individual patient data and subgroup analysis in original report, further and detailed analysis could not be achieved. For instance, survival benefits of local therapy in N2-3 positive, single distant metastasis and surgically treated subgroup of patients. Last but not least, radiotherapy combined with immunotherapy also showed expecting effectiveness for oligometastatic NSCLC patients, but not included in present study due to its lack of survival data.

In conclusion, local aggressive thoracic therapy could prolong 7 months overall and progression-free survival compared with systemic therapy in patients with oligometastatic non-small cell lung cancer. Consolidative local therapy might be a more favorable choice of local therapy to offer survival benefits. Benefits of local therapy for N2-3 positive patients should explored further.

\section{Acknowledgments}

We would like to thank Wenhao Liu for his help in polishing our paper.

Funding: This work was supported by the Natural Science Foundation of Shaanxi Province [grant number: No. 2016JM8087 to Jinbo Zhao] and the National Natural Science Foundation of China [grant number: 81001041 to Jinbo Zhao and 81572252 to Xiaofei Li].

\section{Footnote}

Reporting Checklist: The authors have completed the PRISMA reporting checklist. Available at https://dx.doi. org/10.21037/jtd-21-957

Peer Review File: Available at https://dx.doi.org/10.21037/ jtd-21-957

Conflicts of Interest: All authors have completed the ICMJE uniform disclosure form (available at https://dx.doi. org/10.21037/jtd-21-957). JB Zhao reports funding from Natural Science Foundation of Shaanxi Province (2016JM8087) and funding from National Natural Science Foundation of China (81001041). XF Li reports funding from National Natural Science Foundation of China
(81572252). The other authors have no conflicts of interest to declare.

Ethical Statement: The authors are accountable for all aspects of the work in ensuring that questions related to the accuracy or integrity of any part of the work are appropriately investigated and resolved.

Open Access Statement: This is an Open Access article distributed in accordance with the Creative Commons Attribution-NonCommercial-NoDerivs 4.0 International License (CC BY-NC-ND 4.0), which permits the noncommercial replication and distribution of the article with the strict proviso that no changes or edits are made and the original work is properly cited (including links to both the formal publication through the relevant DOI and the license). See: https://creativecommons.org/licenses/by-nc-nd/4.0/.

\section{References}

1. Sung H, Ferlay J, Siegel RL, et al. Global cancer statistics 2020: GLOBOCAN estimates of incidence and mortality worldwide for 36 cancers in 185 countries. CA Cancer J Clin 2021;71:209-49.

2. National Comprehensive Cancer Network [Internet]. Bethesda: NCCN guidelines for treatment by cancer site: Non-small cell lung cancer; c2021 [cited 2021 May 21]. Avaible online: https://www.nccn.org/professionals/ physician_gls/default.aspx\#nscl.

3. Howlader N, Forjaz G, Mooradian MJ, et al. The Effect of Advances in Lung-Cancer Treatment on Population Mortality. N Engl J Med 2020;383:640-9.

4. Hellman S, Weichselbaum RR. Oligometastases. J Clin Oncol 1995;13:8-10.

5. Parikh RB, Cronin AM, Kozono DE, et al. Definitive primary therapy in patients presenting with oligometastatic non-small cell lung cancer. Int J Radiat Oncol Biol Phys 2014;89:880-7.

6. Petty WJ, Urbanic JJ, Ahmed T, et al. Long-Term Outcomes of a Phase 2 Trial of Chemotherapy With Consolidative Radiation Therapy for Oligometastatic Non-Small Cell Lung Cancer. Int J Radiat Oncol Biol Phys 2018;102:527-35.

7. Collen C, Christian N, Schallier D, et al. Phase II study of stereotactic body radiotherapy to primary tumor and metastatic locations in oligometastatic nonsmall-cell lung cancer patients. Ann Oncol 2014;25:1954-9.

8. De Ruysscher D, Wanders R, van Baardwijk A, et al. Radical treatment of non-small-cell lung cancer patients 
with synchronous oligometastases: long-term results of a prospective phase II trial (Nct01282450). J Thorac Oncol 2012;7:1547-55.

9. Iyengar P, Wardak Z, Gerber DE, et al. Consolidative Radiotherapy for Limited Metastatic Non-Small-Cell Lung Cancer: A Phase 2 Randomized Clinical Trial. JAMA Oncol 2018;4:e173501.

10. Gomez DR, Tang C, Zhang J, et al. Local Consolidative Therapy Vs. Maintenance Therapy or Observation for Patients With Oligometastatic Non-Small-Cell Lung Cancer: Long-Term Results of a Multi-Institutional, Phase II, Randomized Study. J Clin Oncol 2019;37:1558-65.

11. Palma DA, Olson R, Harrow S, et al. Stereotactic Ablative Radiotherapy for the Comprehensive Treatment of Oligometastatic Cancers: Long-Term Results of the SABR-COMET Phase II Randomized Trial. J Clin Oncol 2020;38:2830-8.

12. Wang X, Zeng M. First-line tyrosine kinase inhibitor with or without aggressive upfront local radiation therapy in patients with EGFRm oligometastatic non-small cell lung cancer: Interim results of a randomized phase III, open-label clinical trial (SINDAS) (NCT02893332). ASCO 2020: Annual Meeting of the American-Society-ofClinical-Oncology; 2020 OCT 25-28; Electronic network. Philadelphia: Lippincott Williams \& Wilkins; 2020.

13. Tierney JF, Stewart LA, Ghersi D, et al. Practical methods for incorporating summary time-to-event data into metaanalysis. Trials 2007;8:16.

14. Takagi H, Umemoto T, Group A. A meta-analysis pooling survival curves in randomized controlled trials and propensity-score matched studies of endovascular versus open abdominal aortic aneurysm repair. Int J Cardiol 2014;174:785-8.

15. Gray PJ, Mak RH, Yeap BY, et al. Aggressive therapy for patients with non-small cell lung carcinoma and synchronous brain-only oligometastatic disease is associated with long-term survival. Lung Cancer 2014;85:239-44.

16. Xanthopoulos EP, Handorf E, Simone CB, 2nd, et al. Definitive dose thoracic radiation therapy in oligometastatic non-small cell lung cancer: A hypothesisgenerating study. Pract Radiat Oncol 2015;5:e355-63.

17. Johnson KK, Rosen JE, Salazar MC, et al. Outcomes of a Highly Selective Surgical Approach to Oligometastatic Lung Cancer. Ann Thorac Surg 2016;102:1166-71.

18. Huang SH, Kong QL, Chen XX, et al. Adrenalectomy does not improve survival rates of patients with solitary adrenal metastasis from non-small cell lung cancer. Ther
Clin Risk Manag 2017;13:355-60.

19. Xu Q, Zhou F, Liu H, et al. Consolidative Local Ablative Therapy Improves the Survival of Patients With Synchronous Oligometastatic NSCLC Harboring EGFR Activating Mutation Treated With First-Line EGFRTKIs. J Thorac Oncol 2018;13:1383-92.

20. Giaj-Levra N, Giaj-Levra M, Durieux V, et al. Defining Synchronous Oligometastatic Non-Small Cell Lung Cancer: A Systematic Review. J Thorac Oncol 2019;14:2053-61.

21. Schanne DH, Heitmann J, Guckenberger M, et al. Evolution of treatment strategies for oligometastatic NSCLC patients - A systematic review of the literature. Cancer Treat Rev 2019;80:101892.

22. Goldstraw P, Chansky K, Crowley J, et al. The IASLC Lung Cancer Staging Project: Proposals for Revision of the TNM Stage Groupings in the Forthcoming (Eighth) Edition of the TNM Classification for Lung Cancer. J Thorac Oncol 2016;11:39-51.

23. Dingemans AC, Hendriks LEL, Berghmans T, et al. Definition of Synchronous Oligometastatic Non-Small Cell Lung Cancer-A Consensus Report. J Thorac Oncol 2019;14:2109-19.

24. Endo C, Hasumi T, Matsumura Y, et al. A prospective study of surgical procedures for patients with oligometastatic non-small cell lung cancer. Ann Thorac Surg 2014;98:258-64.

25. Jones GD, Lengel HB, Hsu M, et al. Management of Synchronous Extrathoracic Oligometastatic Non-Small Cell Lung Cancer. Cancers (Basel) 2021;13:1893.

26. De Ruysscher D, Wanders R, Hendriks LE, et al. Progression-Free Survival and Overall Survival Beyond 5 Years of NSCLC Patients With Synchronous Oligometastases Treated in a Prospective Phase II Trial (NCT 01282450). J Thorac Oncol 2018;13:1958-61.

27. Van den Begin R, Engels B, Collen C, et al. The METABANK score: A clinical tool to predict survival after stereotactic radiotherapy for oligometastatic disease. Radiother Oncol 2019;133:113-9.

28. Zhang C, Wang L, Li W, et al. Surgical outcomes of stage IV non-small cell lung cancer: a single-center experience. J Thorac Dis 2019;11:5463-73.

Cite this article as: Zhang $\mathrm{C}, \mathrm{Ma} \mathrm{N}$, Zhang Q, Zheng $\mathrm{K}$, Sun C, Tang X, Li X, Zhao J. Evaluation of local aggressive lung therapy versus systemic therapy in oligometastatic nonsmall cell lung cancer: a systematic review and meta-analysis. J Thorac Dis 2021;13(10):5899-5910. doi: 10.21037/jtd-21-957 
Supplementary

Table S1 Searching strategy of database

\begin{tabular}{ll}
\hline Database & Strategy \\
\hline Pubmed & $((($ local therapy[Title/Abstract] OR surgery[Title/Abstract] OR resection[Title/Abstract] OR stereotactic body \\
& radiotherapy[Title/Abstract] OR SBRT[Title/Abstract] OR radio frequency[Title/Abstract] OR stereotactic ablation body \\
& radiation[Title/Abstract] OR radio therapy[Title/Abstract] OR radiation[Title/Abstract]) AND (systemic therapy[Title/Abstract] \\
& OR chemotherapy[Title/Abstract] OR tyrosine kinase Inhibitor[Title/Abstract] OR immunotherapy[Title/Abstract] OR TKI[Title/ \\
& Abstract] OR PD1[Title/Abstract] OR PDL1[Title/Abstract])) AND (stage IV[Title/Abstract] OR advanced[Title/Abstract] OR \\
& oligometasta*[Title/Abstract] OR metasta*[Title/Abstract])) AND (NSCLC[Title/Abstract] OR non-small cell lung cancer[Title/ \\
& Abstract] OR non small cell lung cancer[Title/Abstract] OR non-small-cell lung cancer[Title/Abstract])
\end{tabular}

Web of (local therapy OR surgery OR resection OR stereotactic body radiotherapy OR SBRT OR radio frequency OR stereotactic knowledge ablation body radiation OR radio therapy OR radiation) AND (systemic therapy OR chemotherapy OR tyrosine kinase Inhibitor OR immunotherapy OR TKI OR PD1 OR PDL1) AND (stage IV OR advanced OR oligometasta* OR metasta*) AND (NSCLC OR non-small cell lung cancer OR non small cell lung cancer OR non-small-cell lung cancer))

Embase ('local therapy':ab,ti OR surgery:ab,ti OR resection:ab,ti OR 'stereotactic body radiotherapy':ab,ti OR sbrt:ab,ti OR 'radio frequency':ab,ti OR 'stereotactic ablation body radiation':ab,ti OR 'radio therapy':ab,ti OR radiation:ab,ti) AND ('systemic therapy':ab,ti OR chemotherapy:ab,ti OR 'tyrosine kinase inhibitor':ab,ti OR immunotherapy:ab,ti OR tki:ab,ti OR pd1:ab,ti OR pdl1:ab,ti) AND ('stage iv':ab,ti OR advanced:ab,ti OR oligometasta*:ab,ti OR metasta*:ab,ti) AND (nsclc:ab,ti OR 'nonsmall cell lung cancer':ab,ti OR 'non small cell lung cancer':ab,ti OR 'non-small-cell lung cancer':ab,ti)

Time interval 2001.1.1-2020.12.31

Table S2 Clinical thoracic stage of patients included

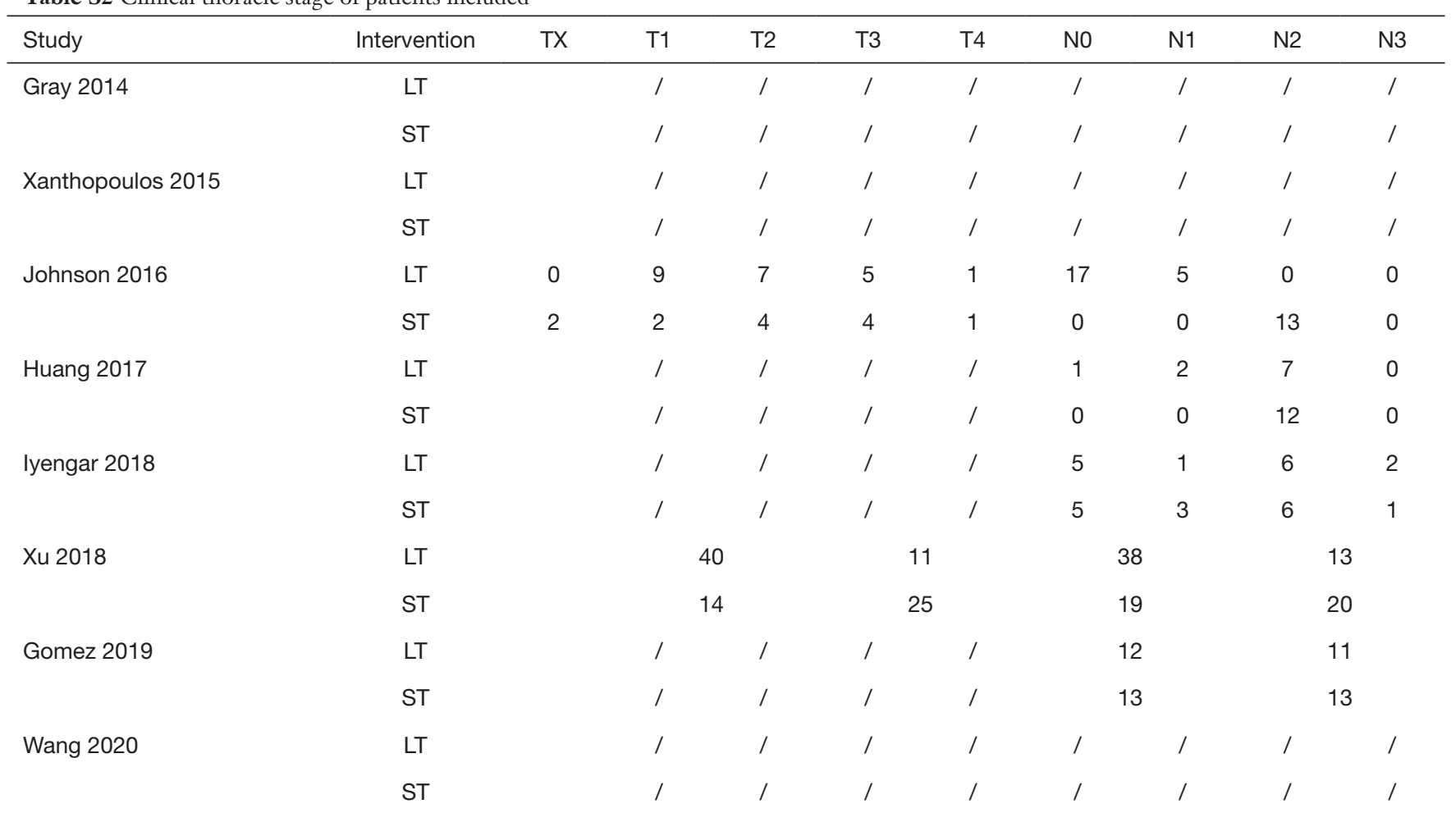

LT, local aggressive lung therapy; ST, systemic therapy. 

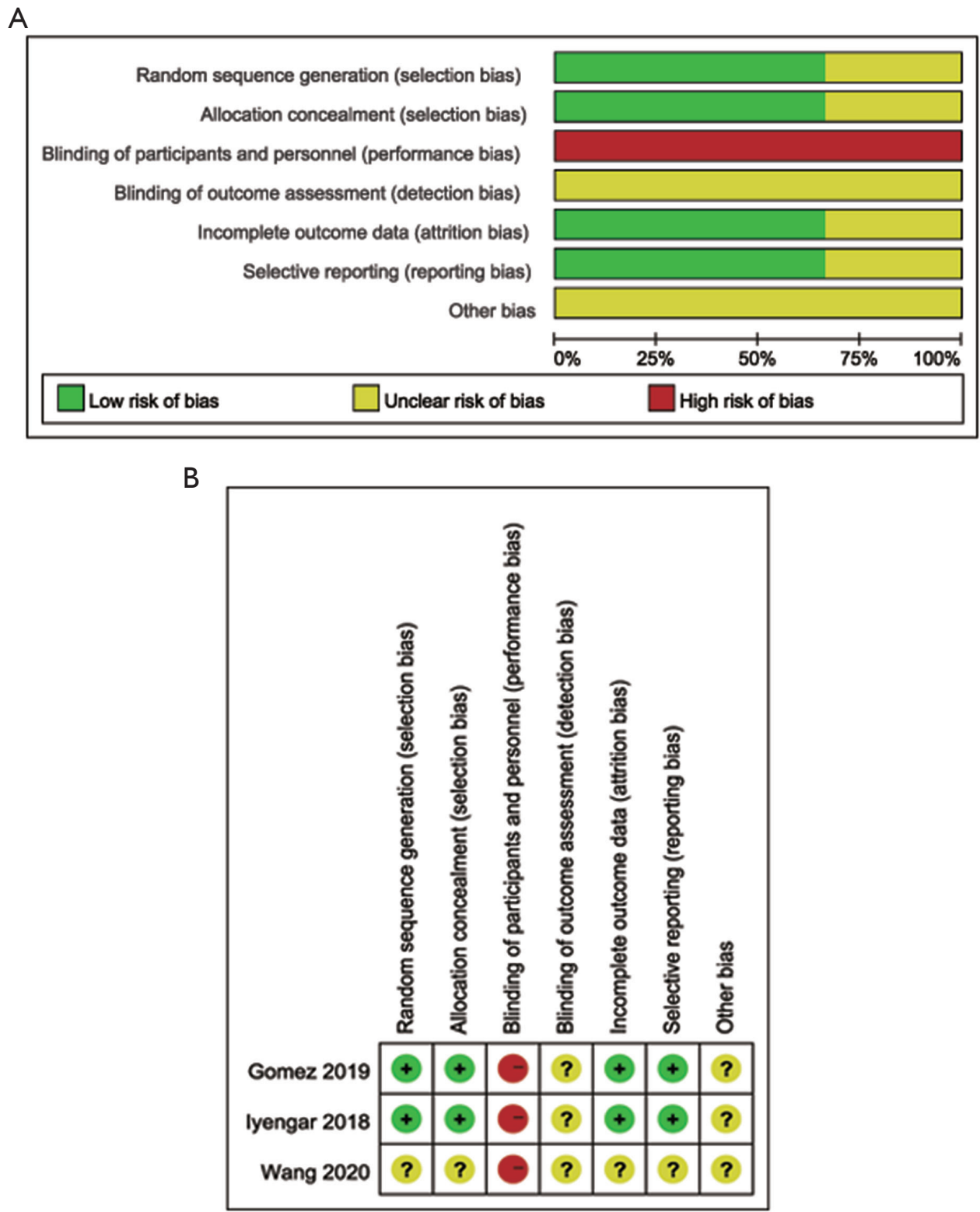

Figure S1 Risk bias table of randomized controlled trials. (A) Bias item presented as percentages; (B) judgements about each risk of bias item. 
Table S3 Newcastle-Ottawa Scale of retrospective studies included

\begin{tabular}{lcccc}
\hline \multirow{2}{*}{ Study } & \multicolumn{3}{c}{ New Ottawa Scale } \\
\cline { 2 - 5 } & Selection & Comparativity & Results & Total \\
\hline Gray 2014 & 3 & 0 & 2 & 5 \\
Xanthopoulos 2015 & 3 & 0 & 2 & 2 \\
Johnson 2016 & 2 & 0 & 2 & 5 \\
Huang 2016 & 3 & 0 & 3 & 6 \\
Xu 2018 & 3 & 0 & & 5 \\
\hline
\end{tabular}

A

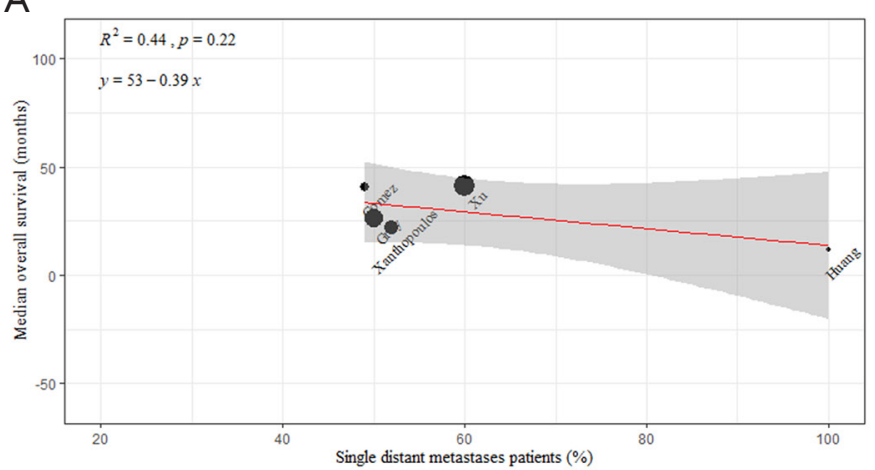

C

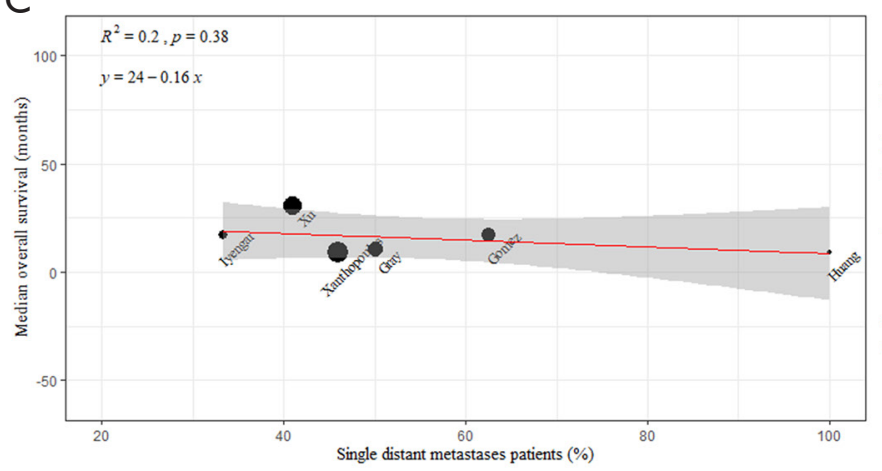

B

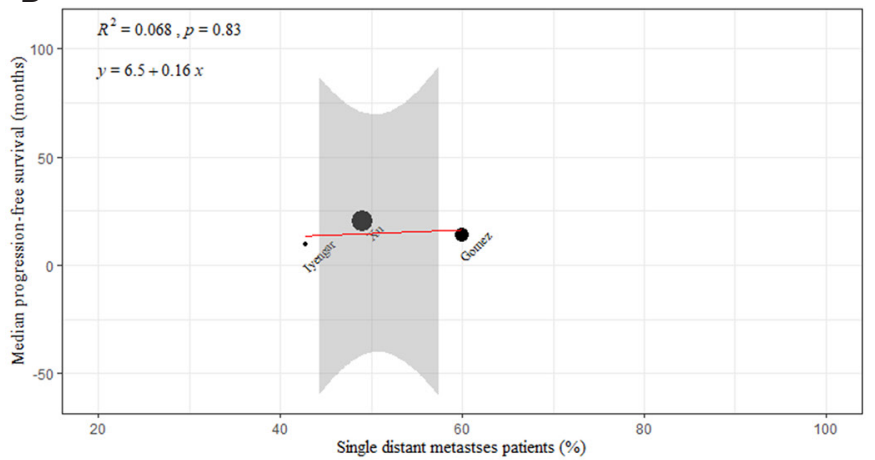

D

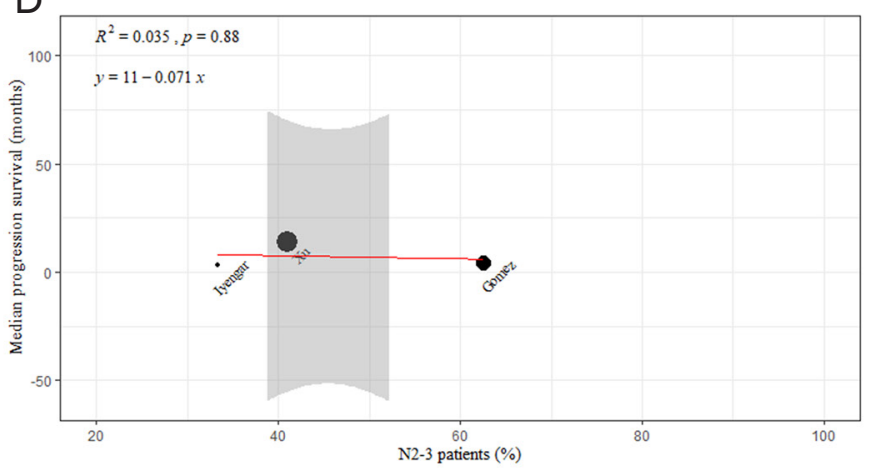

Figure S2 Correlationship between single distant lesion status and median survival time by linear regression analysis. (A) Single distant lesion status and median OS in LT group; (B) single distant lesion status and median OS in ST group; (C) single distant lesion status and median PFS in LT group; (D) single distant lesion status and median PFS in ST group; LT, local aggressive lung therapy; ST, systemic therapy; OS, overall survival; PFS, progression-free survival. 

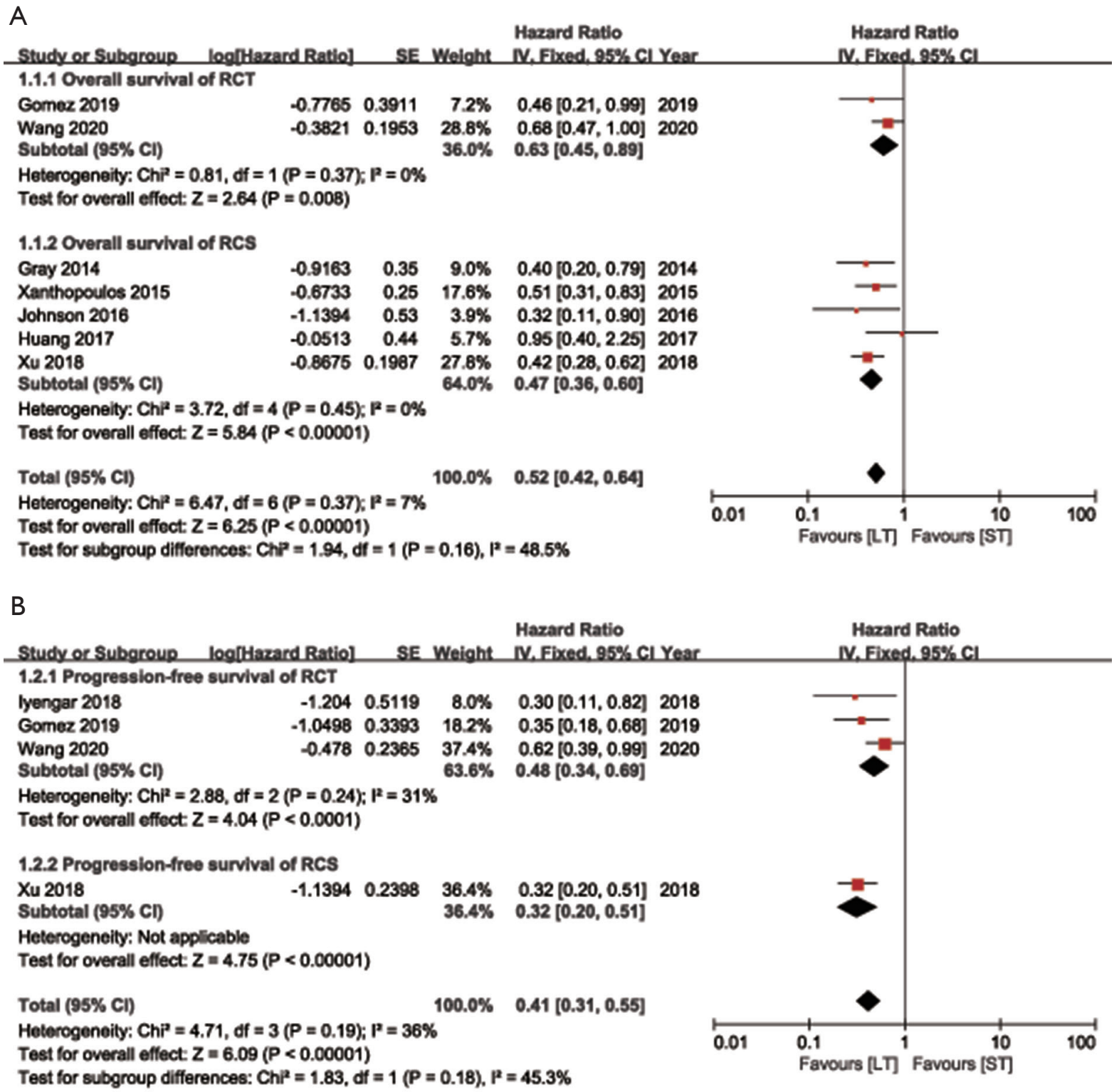

Figure S3 Subgroup analysis of included studies stratified by study type (randomized controlled trials or retrospective cohort studies). (A) Progression-free survival; (B) overall survival. 


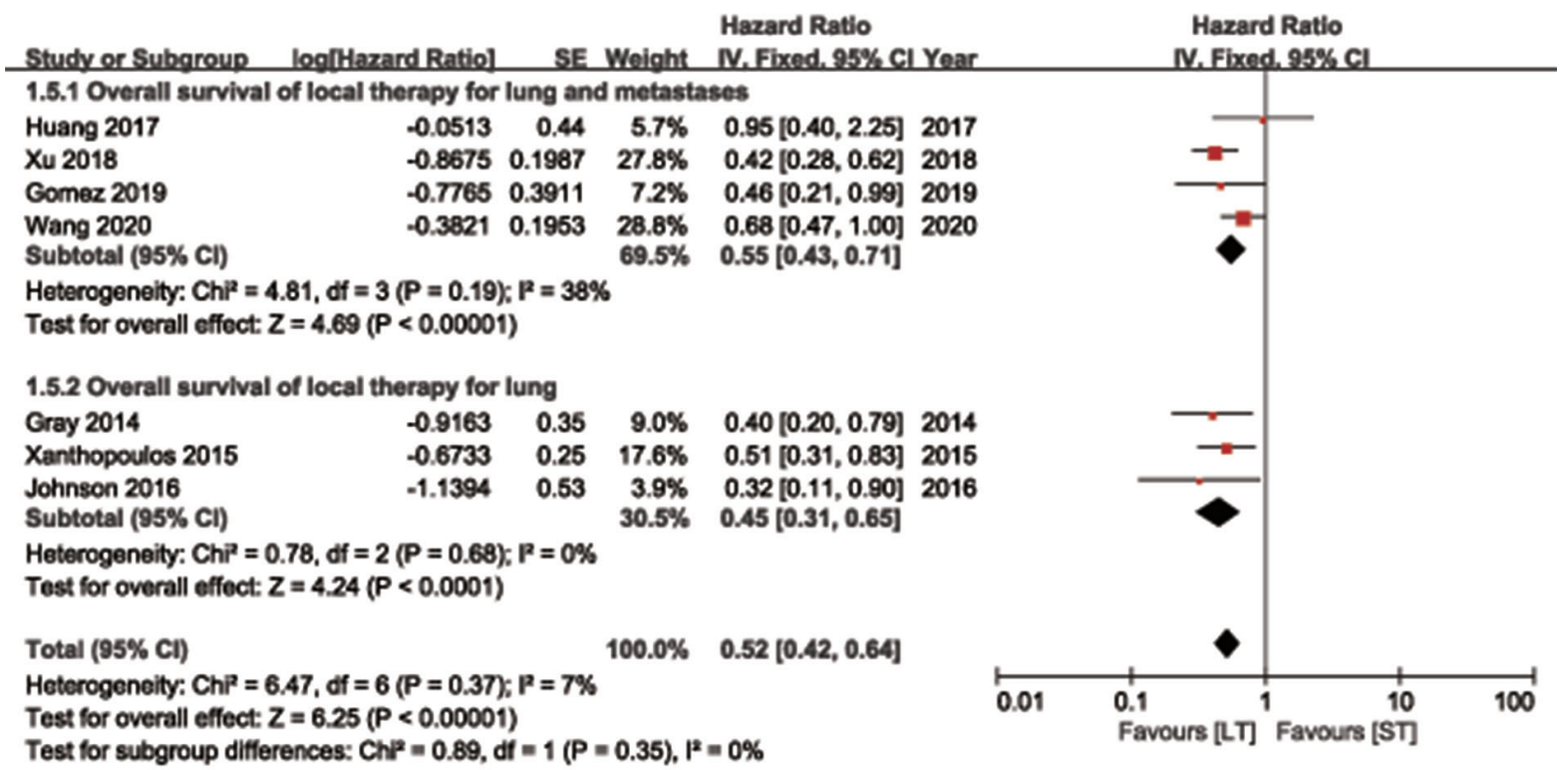

Figure S4 Subgroup overall survival analysis of included studies stratified by local aggressive lung therapy sites (lung only or both lung and metastases). 


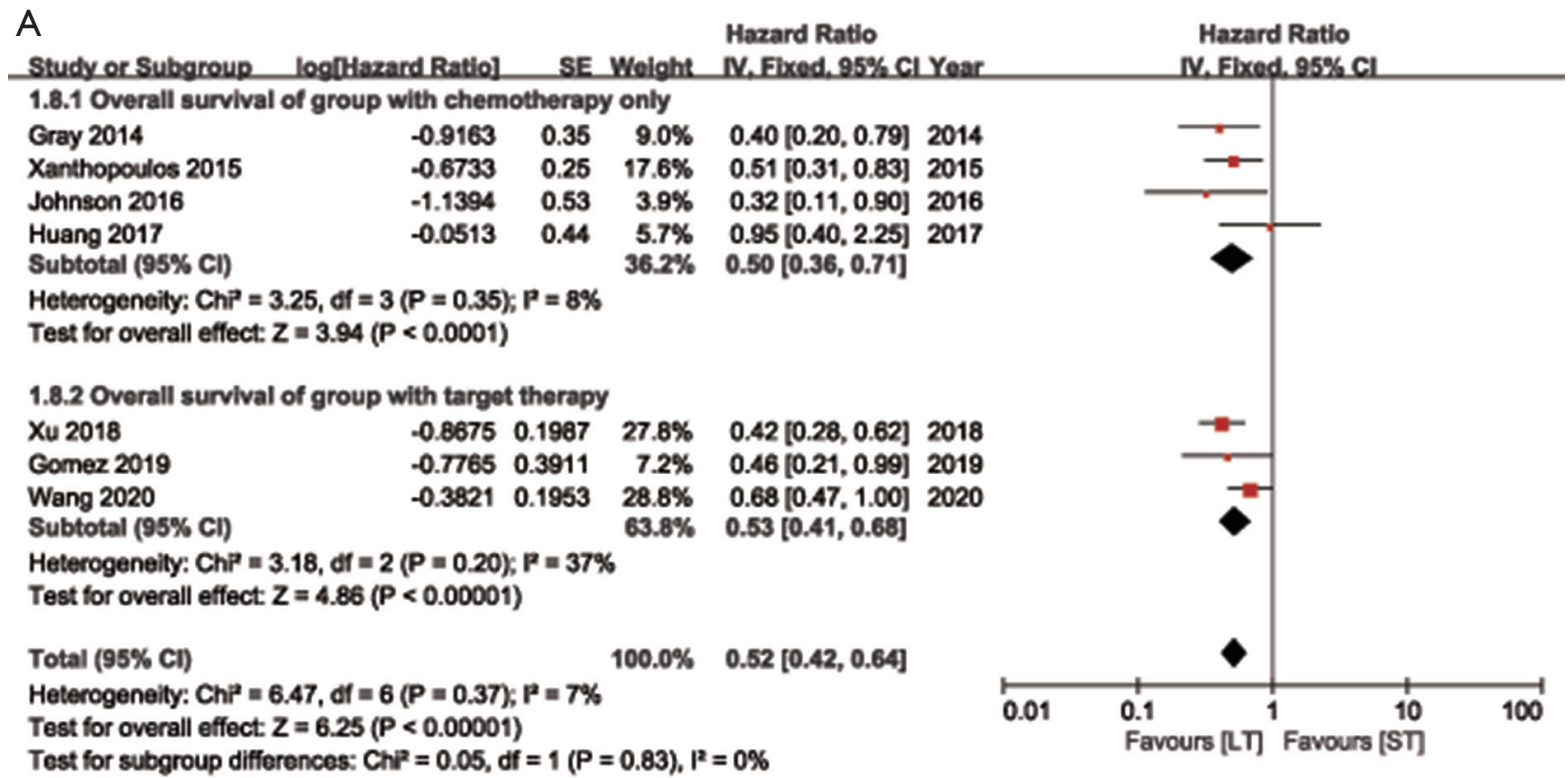

\section{B}

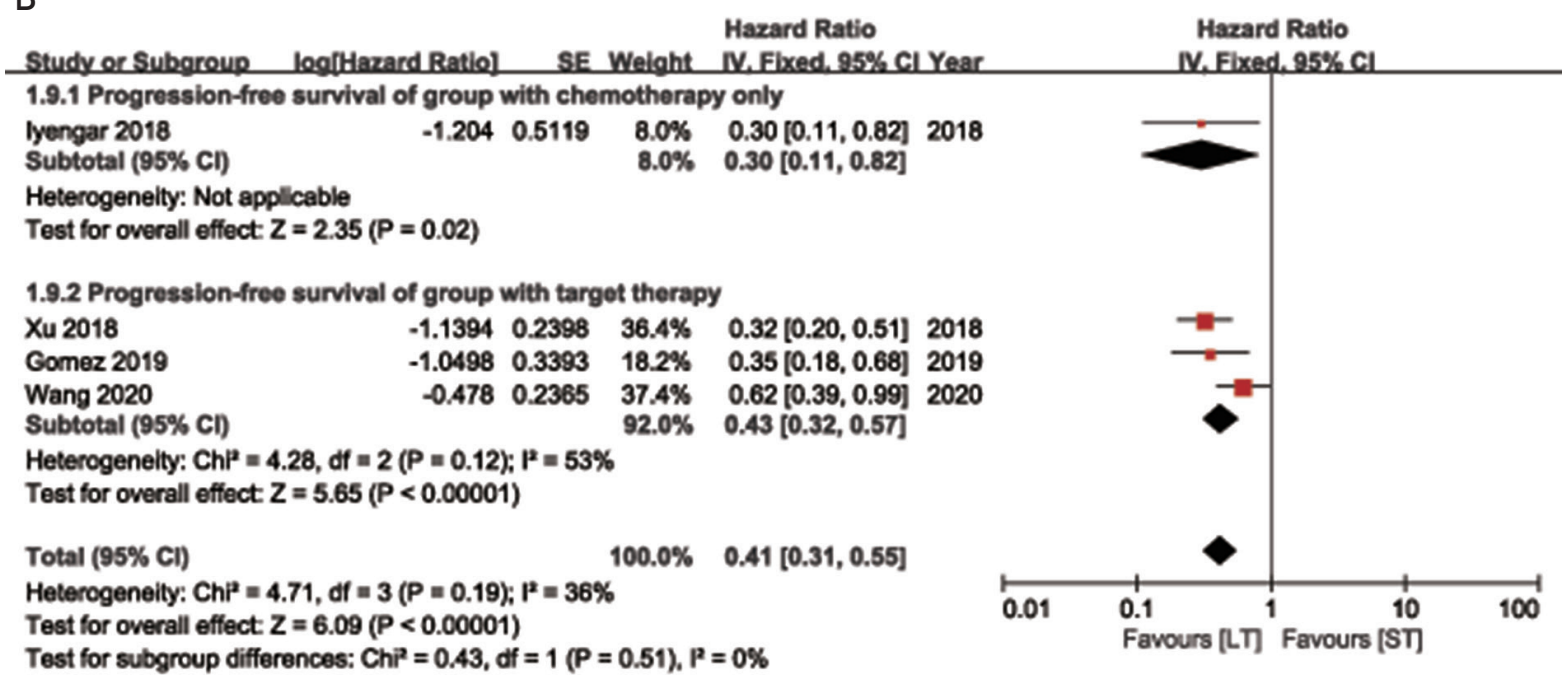

Figure S5 Subgroup analysis of included studies stratified by systemic therapy regimens (chemotherapy alone or targeted therapy); (A) progression-free survival; (B) overall survival.

\begin{tabular}{|c|c|c|c|c|c|c|c|c|c|}
\hline Study or Subgroup & $\begin{array}{r}\text { LT } \\
\text { Exents }\end{array}$ & Iotal & $\begin{array}{r}\text { ST } \\
\text { Exents }\end{array}$ & Iotal & Welght & $\begin{array}{c}\text { Odds Ratio } \\
\text { MH. Flxed. } 95 \% \text { CI }\end{array}$ & $\begin{array}{r}\text { Odds } \\
M . H . \text { Flxe }\end{array}$ & $\begin{array}{l}\text { Ratio } \\
\text { d. } 95 \% \mathrm{Cl}\end{array}$ & \\
\hline Gomez 2019 & 5 & 25 & 3 & 24 & $30.1 \%$ & $1.75[0.37,8.30]$ & & & \\
\hline lyengar 2018 & 4 & 14 & 3 & 15 & $25.5 \%$ & $1.60[0.29,8.90]$ & & & \\
\hline Wang 2020 & 8 & 68 & 4 & 65 & $44.4 \%$ & $2.03[0.58,7.11]$ & & & \\
\hline Total $(95 \%$ Cl) & & 107 & & 104 & $100.0 \%$ & $1.84[0.79,4.29]$ & & & \\
\hline Total events & 17 & & 10 & & & & & & \\
\hline \multicolumn{7}{|c|}{$\begin{array}{l}\text { Heterogeneily: } \mathrm{Ch}^{\mathrm{P}}=0.05, \mathrm{df}=2(\mathrm{P}=0.97) ; \mathrm{P}=0 \% \\
\text { Test for overall effect: } Z=1.41(P=0.16)\end{array}$} & $\begin{array}{l}0.1 \\
\text { Favours [LT] }\end{array}$ & Favours [ST] & 100 \\
\hline
\end{tabular}

Figure S6 Forest plot of merged odds ratio of adverse effects between local aggressive lung therapy and systemic therapy groups. 
Table S4 Adverse effects reported in local therapy and systemic therapy groups

\begin{tabular}{|c|c|c|c|c|}
\hline Study and event & \multicolumn{2}{|c|}{ Local therapy } & \multicolumn{2}{|c|}{ Systemic therapy } \\
\hline \multicolumn{5}{|l|}{ lyengar 2018} \\
\hline Gastrointestinal & 6 & & 6 & \\
\hline Hematologic & 4 & $1(7.1 \%)$ & 6 & $2(13.4 \%)$ \\
\hline Respiratory & 2 & $2(14.2 \%)$ & 5 & \\
\hline Skin & 1 & & & \\
\hline $\mathrm{NOS}^{\dagger}$ & 5 & & 7 & \\
\hline \multicolumn{5}{|l|}{ Gomez 2019} \\
\hline Anemia & & $1(4.0 \%)$ & & $1(4.2 \%)$ \\
\hline Extremity edema & & & & $1(4.2 \%)$ \\
\hline Esophagitis & 1 & $2(8.0 \%)$ & & \\
\hline Rib fracture & & $1(4.0 \%)$ & & \\
\hline \multicolumn{5}{|l|}{ Wang 2020} \\
\hline Pneumonitis & NA & $5(7.3 \%)$ & NA & $2(2.9 \%)$ \\
\hline Esophagitis & NA & $3(4.4 \%)$ & NA & $2(3.0 \%)$ \\
\hline
\end{tabular}

NA, not applicable; NOS is not defined in original study.

Table S5 Adverse effects reported in local therapy group

\begin{tabular}{|c|c|c|}
\hline Study and event & \multicolumn{2}{|c|}{ Addition of local therapy } \\
\hline \multicolumn{3}{|c|}{ Xanthopoulos 2015} \\
\hline Pneumonitis & $14 \%$ & $14 \%$ \\
\hline Esophagitis & $24 \%$ & $21 \%$ \\
\hline Pneumonitis & NA & $7.7 \%$ \\
\hline Esophagitis & NA & $16.9 \%$ \\
\hline
\end{tabular}

NA, not applicable. 


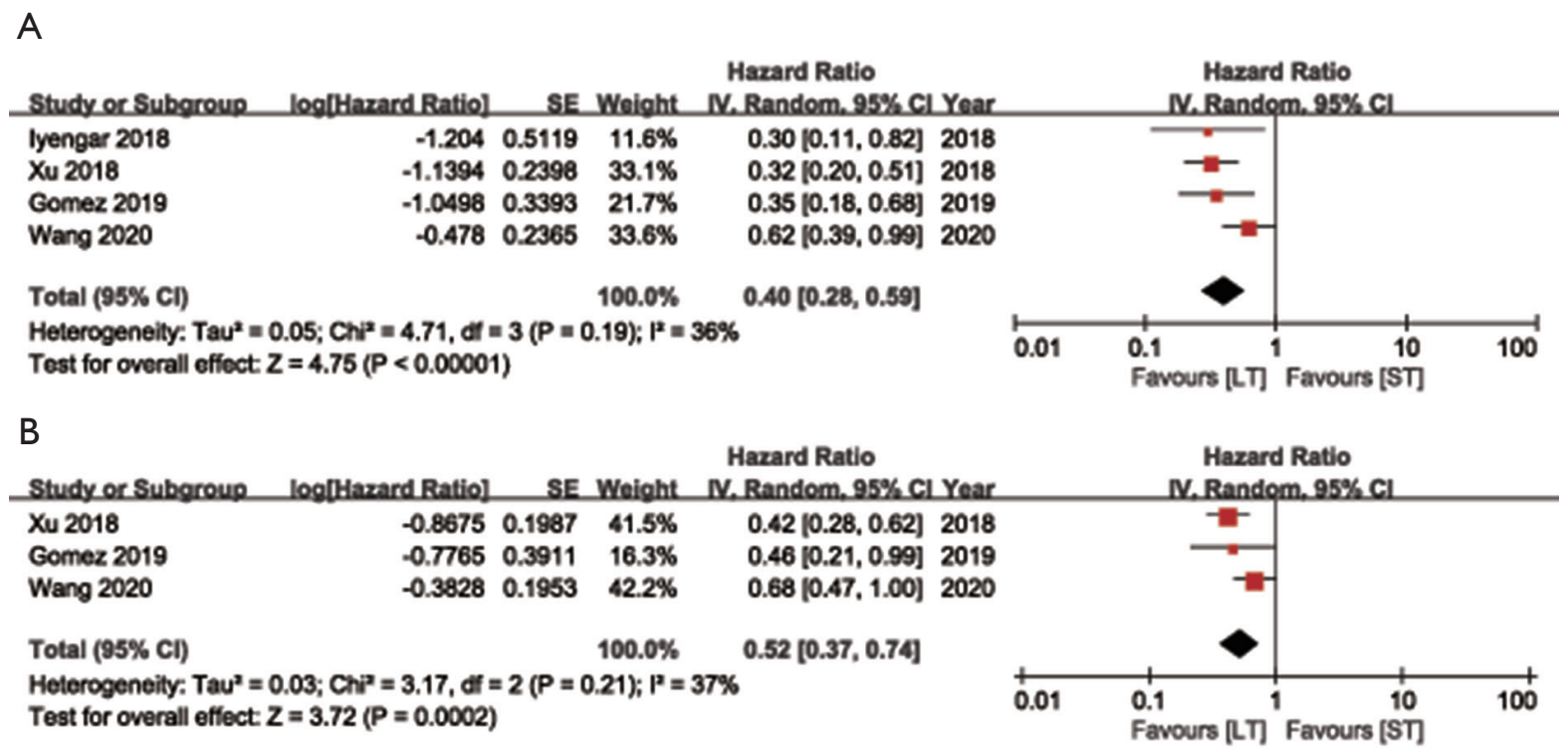

Figure S7 Sensitivity analysis by excluding low quality retrospective cohort studies. (A) Progression-free survival; (B) overall survival. 